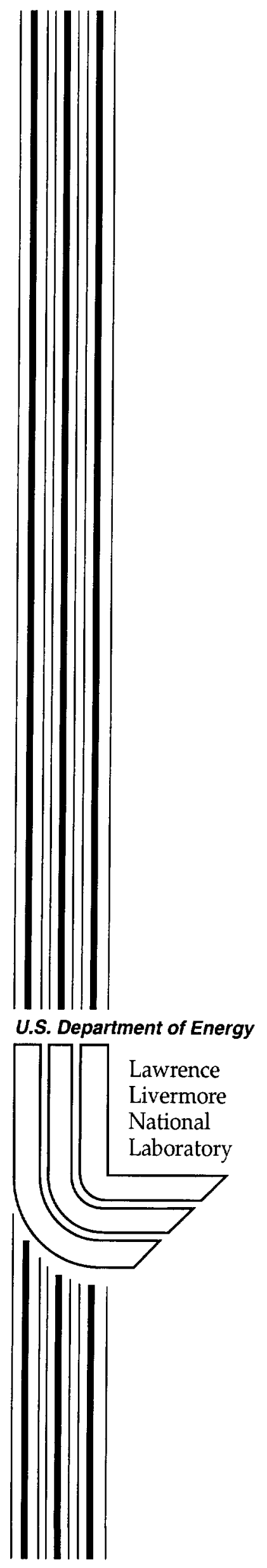

UCRL-ID-147750

\title{
Barrier Foil Heating Simulations Using LASNEX
}

D. D.-M. Ho

March 12, 2002 


\section{DISCLAIMER}

This document was prepared as an account of work sponsored by an agency of the United States Government. Neither the United States Government nor the University of California nor any of their employees, makes any warranty, express or implied, or assumes any legal liability or responsibility for the accuracy, completeness, or usefulness of any information, apparatus, product, or process disclosed, or represents that its use would not infringe privately owned rights. Reference herein to any specific commercial product, process, or service by trade name, trademark, manufacturer, or otherwise, does not necessarily constitute or imply its endorsement, recommendation, or favoring by the United States Government or the University of California. The views and opinions of authors expressed herein do not necessarily state or reflect those of the United States Government or the University of California, and shall not be used for advertising or product endorsement purposes.

This work was performed under the auspices of the U. S. Department of Energy by the University of California, Lawrence Livermore National Laboratory under Contract No. W-7405-Eng-48.

This report has been reproduced directly from the best available copy.

Available electronically at http://www.doc.gov/bridge

Available for a processing fee to U.S. Department of Energy

And its contractors in paper from

U.S. Department of Energy

Office of Scientific and Technical Information

$$
\text { P.O. Box } 62
$$

Oak Ridge, TN 37831-0062

Telephone: (865) 576-8401

Facsimile: (865) 576-5728

E-mail: reports@adonis.osti.gov

Available for the sale to the public from

U.S. Department of Commerce

National Technical Information Service 5285 Port Royal Road

Springfield, VA 22161

Telephone: (800) 553-6847

Facsimile: (703) 605-6900

E-mail: orders@ntis.fedworld.gov

Online ordering: http://www.ntis.gov/ordering.htm

\section{OR}

Lawrence Livermore National Laboratory

Technical Information Department's Digital Library

http://www.llnl.gov/tid/Library.html 


\title{
Barrier Foil Heating Simulations Using LASNEX
}

\author{
Darwin D.-M. Ho
}

\begin{abstract}
Summary
It is necessary to place a barrier foil in front of the X-ray converter target to prevent the backstreaming ions. This research note presents the simulations of foil heating using the latest EOS tables. LASNEX simulations are carried out using both DARHT-II and ETA-II beam parameters. Results for all the foils studied here, using the DARHT-II beam parameters, show that the integrated line density along the axis at the end of the $4^{\text {th }}$ pulse remains essentially unchanged even if the foils are heated by beams with relatively small beam spot sizes. The temperature can reach up to $3000{ }^{\circ} \mathrm{C}$ on graphite foil but can only reach several hundred degree Celsius on Mylar foil. Simulations also show that ETA-II beam can create a "burn-through" hole on all the foils except graphite and diamond foils, which may require pre-heat. The threshold beam spot size required for hole formation will be compared with LASNEX simulation for the purpose of code verification.
\end{abstract}

\section{Introduction}

Placing a foil in front of the X-ray converter target can stop the backstreaming ions and consequently, beam disruption can be prevented. For this concept to work, the foil must preserve the integrated line density, in spite of hydro expansion resulted from beam heating, before the end of the $4^{\text {th }}$ pulse.

In this note, we summarize the results from a series of LASNEX simulations for foil heating by e-beams using the latest EOS tables. These new EOS tables properly include material properties in the two-phase regime. Both the DARHT-II and the ETA-II beam parameters are used for the simulations. Simulations with the DARHT-II parameters are used to identify foil materials that can survive all four pulses. Simulations with the ETA-II parameters are used to study foil heating in the ETA-II experiments. The ETA-II results will be compared with simulations for the purpose of code verification. The foil configurations used in this set of simulations has a thickness of $1 \mathrm{mil}(0.0025 \mathrm{~cm})$ and they are fabricated from various materials, e.g., beryllium, .graphite, diamond, kapton, and Mylar.

\section{Simulations of foil heating with the DARHT-II and ETA-II beams}

The DARHT-II beam has four pulses and each pulse has an energy of 18.4 $\mathrm{MeV}$ and a current of $2 \mathrm{kA}$. The ETA-II beam has an energy of $5.5 \mathrm{MeV}$ and a 
current of $1.6 \mathrm{kA}$. We assume a flat-top pulse with $50 \mathrm{~ns}$ duration. The amount of energy deposited in the foil by the e-beam is calculated by J. McCarrick using the Monte Carlo code MCNP. The values of the energy deposited per electron in various foil materials with thickness of 1 mil are listed in the following table.

Table I. Energy deposit data

\begin{tabular}{|l|l|l|l|}
\hline Material & Density $\left(\mathrm{g} / \mathrm{cm}^{3}\right)$ & $\begin{array}{l}\text { Energy deposited } \\
(\mathrm{MeV} / \mathrm{e}) \text { for } \\
5.5 \mathrm{MeV} \text { beam }\end{array}$ & $\begin{array}{l}\text { Energy deposited } \\
\left(\mathrm{MeV} / \mathrm{e}^{-}\right) \text {for } \\
18.4 \mathrm{MeV} \text { beam }\end{array}$ \\
\hline $\mathrm{B}_{4} \mathrm{C}$ & 2.52 & $8.54 \mathrm{e}-3$ & $8.76 \mathrm{e}-3$ \\
\hline Graphite & 2.25 & $7.24 \mathrm{e}-3$ & $7.42 \mathrm{e}-3$ \\
\hline Diamond & 3.51 & $12.5 \mathrm{e}-3$ & $12.7 \mathrm{e}-3$ \\
\hline Mylar & 1.395 & $5.4 \mathrm{e}-3$ & $5.5 \mathrm{e}-3$ \\
\hline Kapton & 1.41 & $5.62 \mathrm{e}-3$ & $5.74 \mathrm{e}-3$ \\
\hline
\end{tabular}

\section{Foil simulations with DARHT-II parameters}

Graphite and diamond foils:

Among the foils made of different materials, only the carbon and diamond foils can survive all four pulses without substantial hydro expansion. Graphite and diamond have very similar characteristics in terms of temperature rise. Figures $1 \mathrm{a}$ and $1 \mathrm{~b}$ show the axial density vs time at the center of the carbon foils heated by beam with FWHM spot size of 2 and $4.5 \mathrm{~mm}$, respectively. These figures show that carbon foils start to disintegrate during the $4^{\text {th }}$ pulse for the case with FWHM spot size of $2 \mathrm{~mm}$. However, the axial density is still relatively high, e.g. above $1 \mathrm{~g} / \mathrm{cm}^{3}$, at the end of the $4^{\text {th }}$ pulse as shown in Fig. 1a. Furthermore, the integrated line density along the axis is essentially unchanged from its initial value. Therefore, graphite foil is not transparent to the backstreaming ions for FWHM spot size as small as $2 \mathrm{~mm}$. The corresponding axial temperatures for these two cases are shown in Figs. 2a and $2 b$. The radial temperature profiles on the surface of the foil for these two cases, at $t=1 \mu \mathrm{s}$, are shown in Figs. $2 \mathrm{c}$ and $2 \mathrm{~d}$. Note that because the foil is very thin and also there is only limited hydro expansion, the temperature is essentially uniform across the foil.

$\mathrm{B}_{4} \mathrm{C}$ foils:

For FWHM spot size of $2 \mathrm{~mm}$, the density and temperature evolution at the center of the foil are shown in Figs. 3a and $3 \mathrm{~b}$. The integrated line density at $t$ $=0$ and $1.8 \mu \mathrm{s}$ are shown in Fig. 3c. There are considerable reduction of line density at $1.8 \mu$ s because of the rapid hydro-expansion experienced by the foil. For the purpose of stopping backstreaming ions, we may therefore need to 
reduce the hydro-expansion by increasing the spot size. If the FWHM spot size is increased to $4.5 \mathrm{~mm}$, the maximum temperature at the end of the $4^{\text {th }}$ pulse drops to about $1000{ }^{\circ} \mathrm{C}$ and there is no significant drop in foil density and the foil can therefore stop the backstreaming ions. Based on the simulations for these two spot sizes, we can expect that there should be no significant drop in the integrated line density if the FWHM spot size is about $3.5 \mathrm{~mm}$.

Mylar foils:

For FWHM spot size of $3.5 \mathrm{~mm}$, the density and temperature evolution at the center of the foil are shown in Figs. $4 a$ and $4 b$, respectively. The cooling from the rapid hydro expansion causes the temperature to drop after each pulse as shown in Fig. $4 \mathrm{~b}$. The integrated line densities at $\mathrm{t}=0$ and $2 \mu \mathrm{s}$ are shown in Fig. $4 c$. This figure shows that the reduction in integrated line density is relatively small, e.g., less than $10 \%$, at the end of the $4^{\text {th }}$ pulse despite of the fact that the foil density drops substantially because of the expansion. Therefore, the foil should be able to stop the backstreaming ions based on this hydro calculation. However, it is necessary to have a metallic coating on the Mylar foil to prevent arcing which can result in ion production. Whether this coating still remains conductive after the foil undergoes the substantial expansion as shown in Fig. 4d cannot be addressed by the hydro simulation alone.

However, placing the metallic coating in the middle, instead of on the surface, of the Mylar foil, can probably circumvent this potential problem. This can be done, for example, by stacking two foil with the same thickness together with the metallic coating between the two foils, or by putting two Mylar foils on the front and back of a conducting foil and form a "sandwich" foil.

The configuration of such a sandwich foil used in our simulation has a 0.1mil thick $\mathrm{B}_{4} \mathrm{C}$ foil placed between two 0.5-mil thick Mylar foils. The FWHM spot size is $3.5 \mathrm{~mm}$. At the end of the $4^{\text {th }}$ pulse, the axial density of the $\mathrm{B}_{4} \mathrm{C}$ foil is essentially unchanged as shown in Fig. 5 a and therefore the conductivity of the foil is preserved. The temperature of the Mylar foil remains below $300{ }^{\circ} \mathrm{C}$ at all time. Although the density of the Mylar foils decrease substantially as shown in this figure, there is essentially no change in the integrated line density of this sandwich foil at the end of the $4^{\text {th }}$ pulse as shown in Fig. $5 \mathrm{~b}$. Consequently, backstreaming ions can be stopped. The overall expanded configuration of this sandwich foil at the end of the $4^{\text {th }}$ pulse is shown in Fig. 5c.

\section{Kapton foils:}

The performance of the kapton foil is similar to that of the Mylar foil except the temperature of the kapton foil is higher than that of the Mylar foil if heated by beam with the same spot size. Figure 6a shows that temperature vs time in the middle of the foil when heated by beam with FWHM spot size of 3.5 $\mathrm{mm}$. Figure $6 \mathrm{~b}$ shows the integrated line density at $\mathrm{t}=0$ and $2 \mu \mathrm{s}$. The integrated line density at the end of the $4^{\text {th }}$ pulse decreases less than $10 \%$ and therefore we expect that the backstreaming ion can be stopped. 


\section{Foil simulations with the ETA-II beam parameters}

A series of foil heating experiments using ETA-II beam with different spot radius will be performed. The experimental result will be compared with simulations to verify the code's capability of predicting foil melting temperature and the temperature of vaporization. Simulations show that ETA-II beam should be able to cause foil melting (e.g., hole formation) on all the foil materials except graphite and diamond. For graphite and diamond, the ability for ETA-II beam to vaporize these foils is marginal.

For the heating of graphite foil by beam with FWHM spot size of $1 \mathrm{~mm}$, the density and temperature vs time are shown in Figs. $7 \mathrm{a}$ and $7 \mathrm{~b}$, respectively. The foil configuration at $500 \mathrm{~ns}$ is shown in Fig. 7c. This simulation shows that if there is no preheat, the ability for the ETA-II beam to vaporize graphite foil is marginal.

For $\mathrm{B}_{4} \mathrm{C}$ foil, simulation shows that there is substantial foil expansion if the FWHM spot size is $1.5 \mathrm{~mm}$.

For Mylar foil, simulation show that the threshold FWHM spot radius for hole formation is between 4.5 and $5.5 \mathrm{~mm}$, e.g., substantial foil expansion is observed at FWHM spot size of $4.5 \mathrm{~mm}$ and foil does not melt when the spot size increases to $5.5 \mathrm{~mm}$.

\section{Conclusion}

LASNEX simulations of foil heating with DARHT-II parameters show that the integrated line density at the end of the $4^{\text {th }}$ pulse is essentially unchanged if the FWHM spot size is greater than $2 \mathrm{~mm}$ for graphite and diamond foils and greater than $3.5 \mathrm{~mm}$ for all the other foils. Consequently, the backstreaming ions can be stopped. By putting the conductive coating in the middle of the kapton and Mylar foils, or by creating a sandwich foil, the conductive coating can probably be preserved even if the kapton and Mylar foils experience substantial hydro expansion. Simulations of ETA-II heating show that ETA-II can cause hole formation on all the foils except on carbon and diamond foils which may require preheat.

This work was performed under the auspices of the U.S. Department of Energy by the University of California, Lawrence Livermore National Laboratory under Contract No. W-7405-Eng-48. 
(a) FWHM spot size $=2 \mathrm{~mm}$

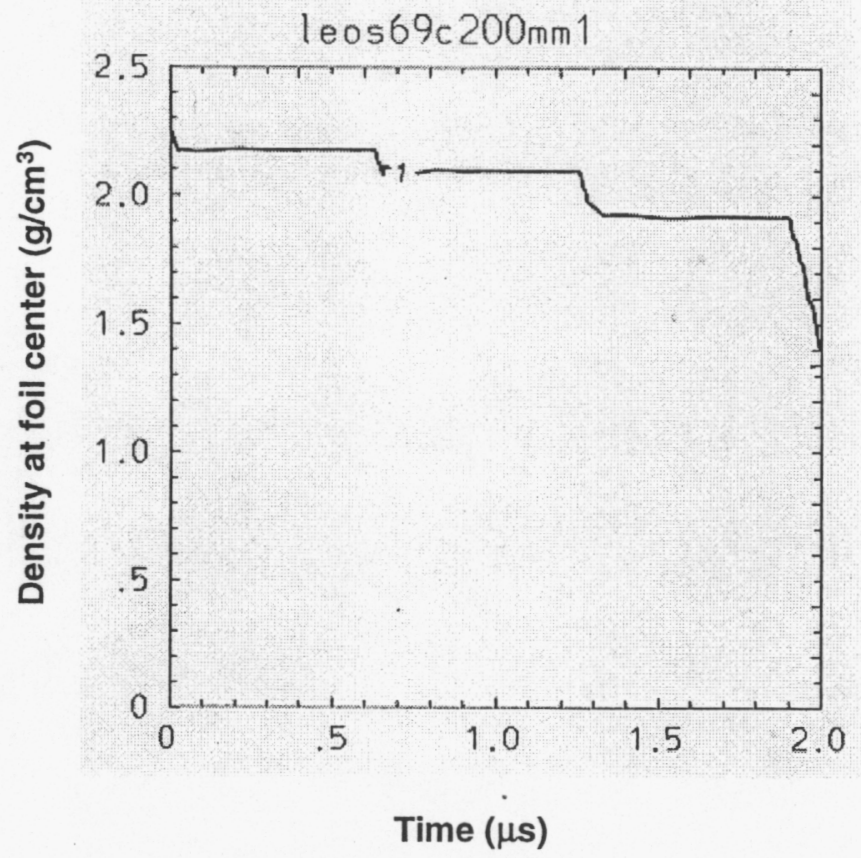

(b) FWHM spot size $=4.5 \mathrm{~mm}$

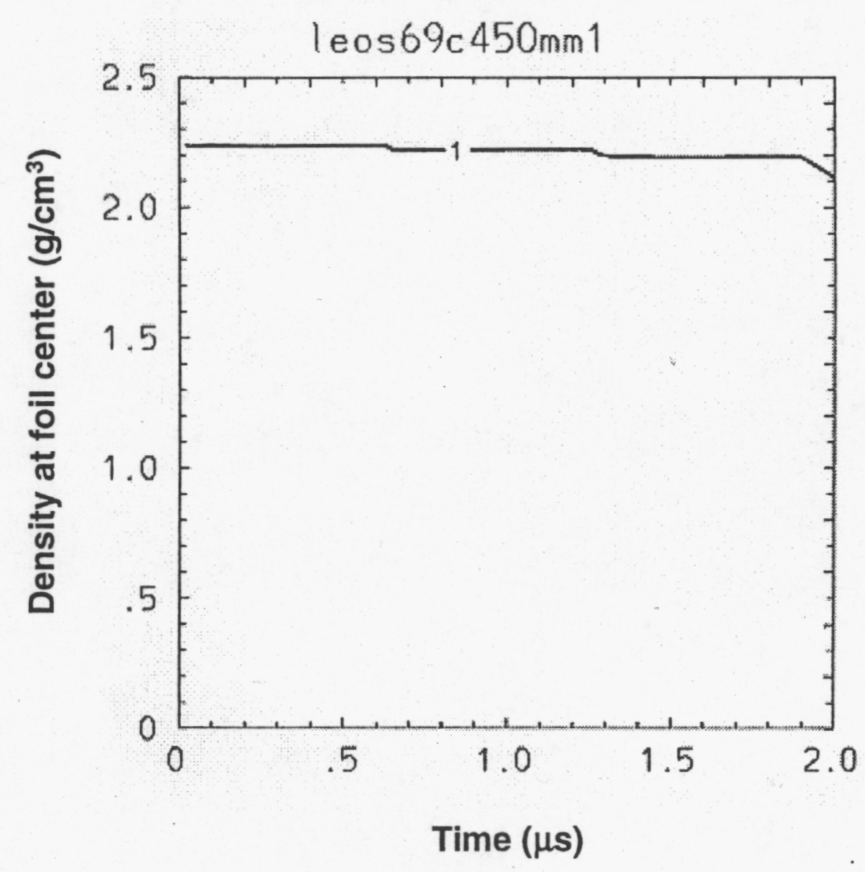

Fig. 1 Density vs time plots for graphite foil heated by DARHT-II beam 
(a) FWHM spot size $=2 \mathrm{~mm}$

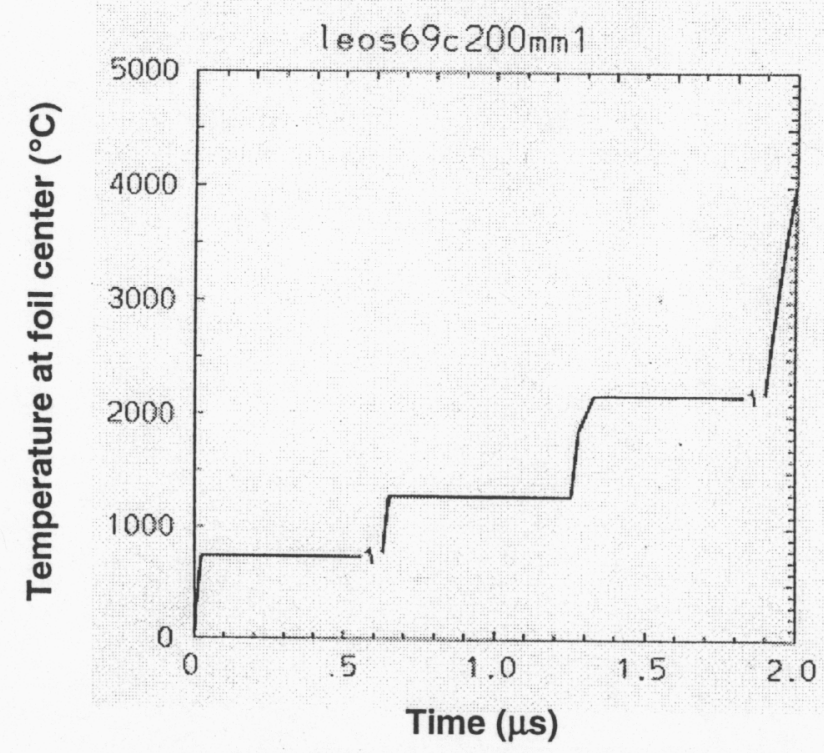

(c) FWHM spot size $=2 \mathrm{~mm}, \mathrm{t}=1 \mu \mathrm{s}$

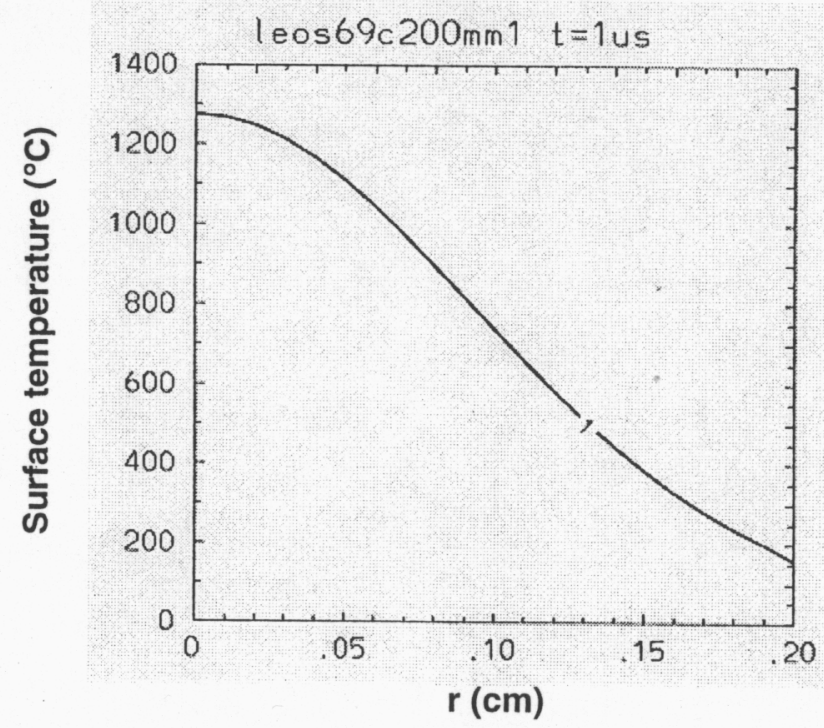

(b) FWHM spot size $=\mathbf{4 . 5} \mathrm{mm}$

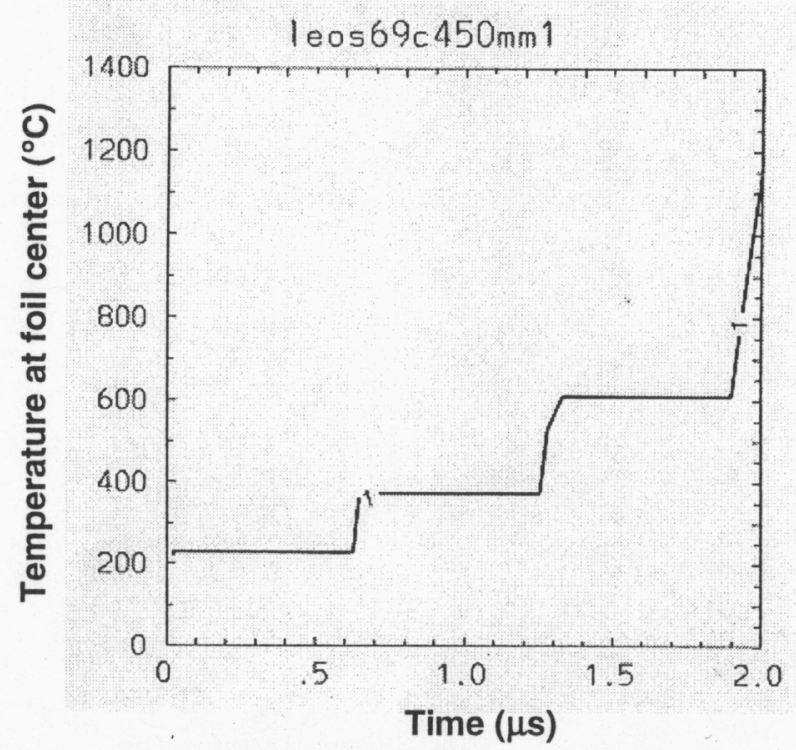

(d) FWHM spot size $=4.5 \mathrm{~mm}, \mathrm{t}=1 \mu \mathrm{s}$

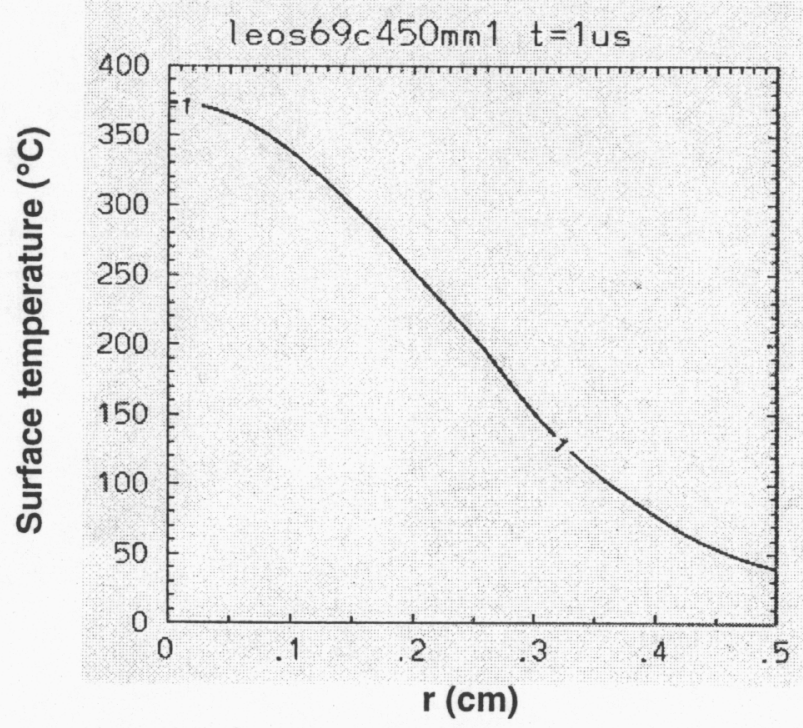

Fig. 2 Graphite foil heated by DARHT-II beam with FWHM spot size of 2 and $4.5 \mathrm{~mm}$ 

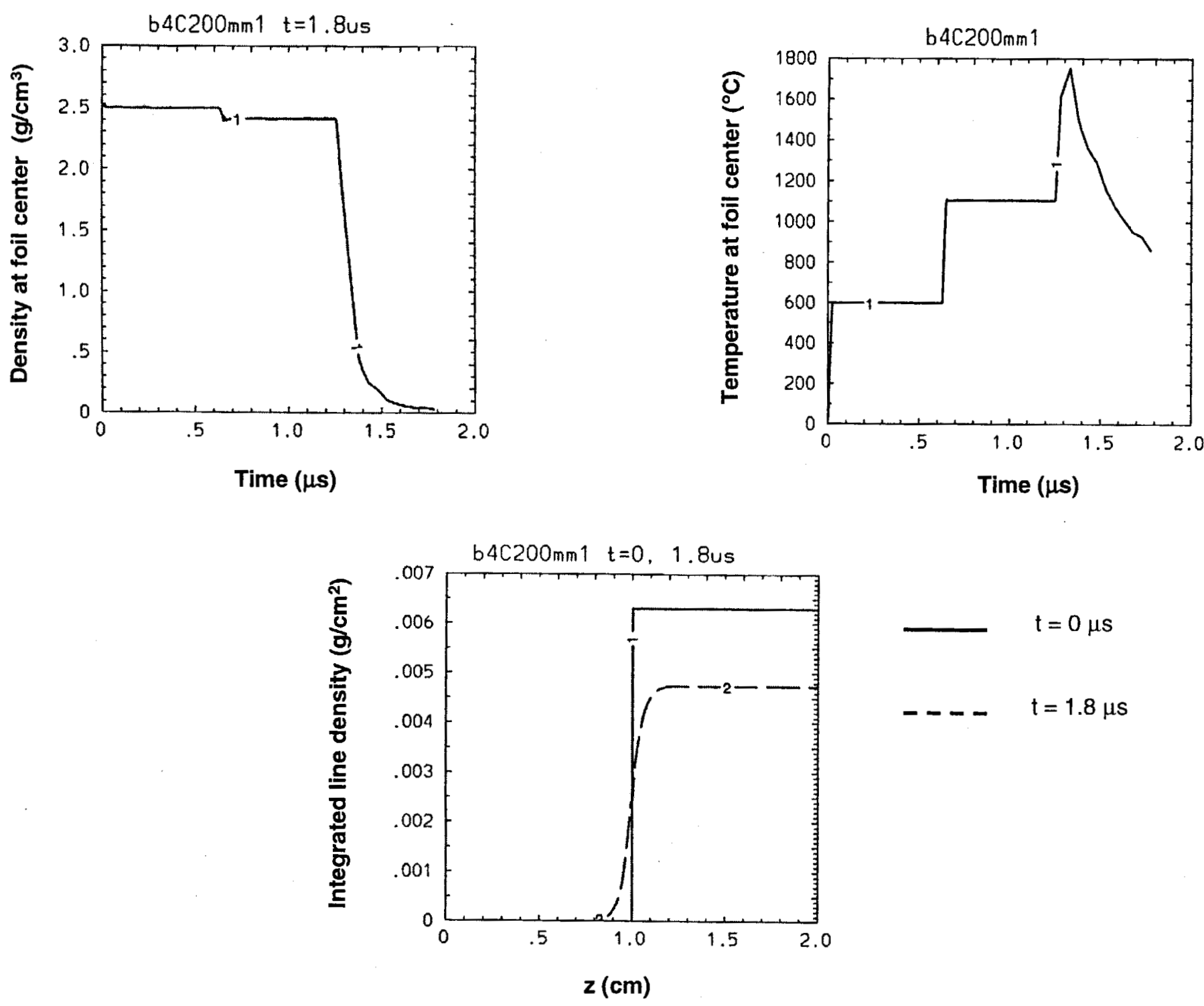

Fig. $3 \mathrm{~B}_{4} \mathrm{C}$ foil heated by DARHT-\|l beam with FWHM spot size of $2 \mathrm{~mm}$ 

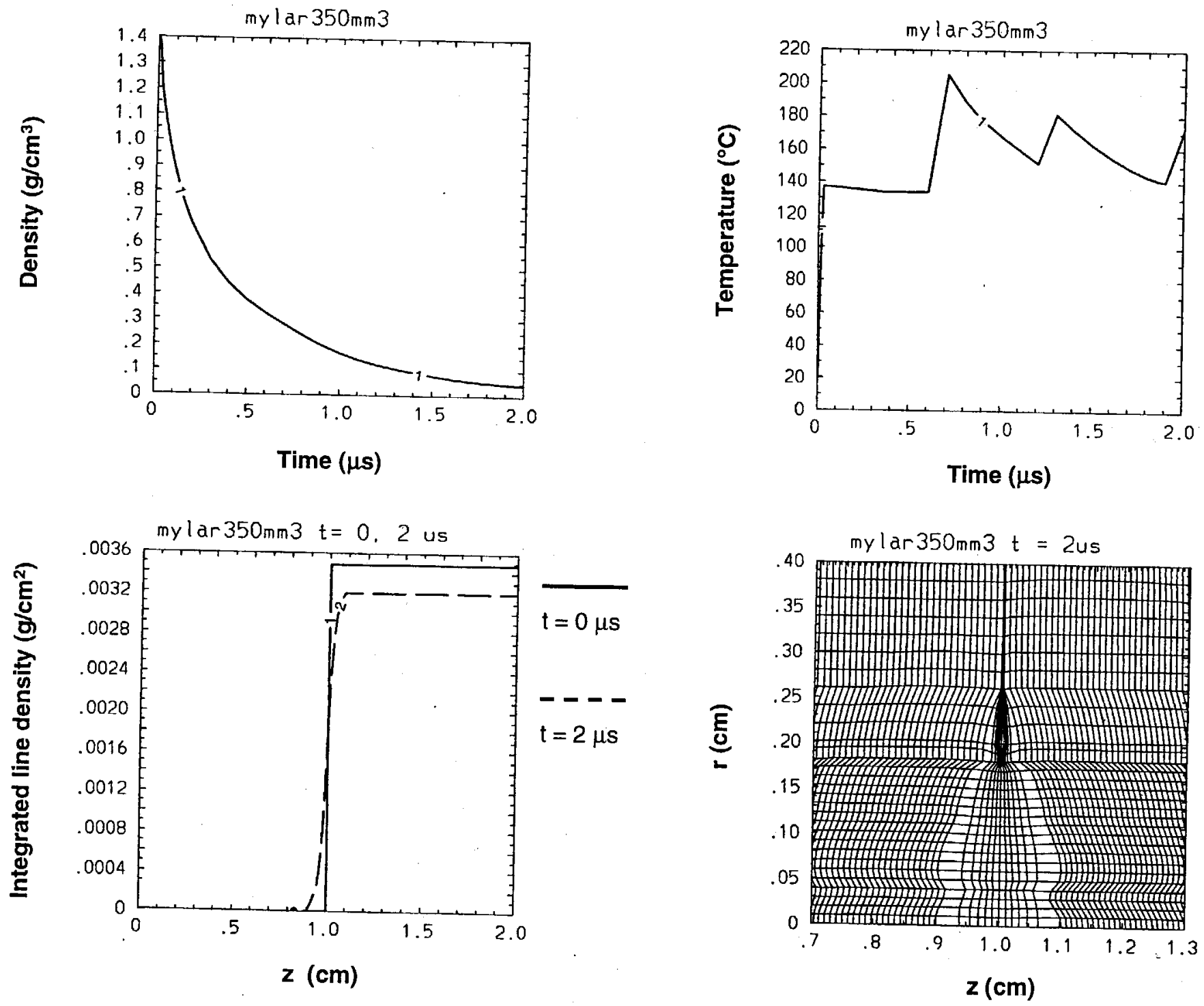

Fig. 4 Mylar foil heated by DARHT-II beam with FWHM spot size of $3.5 \mathrm{~mm}$ 
(a)

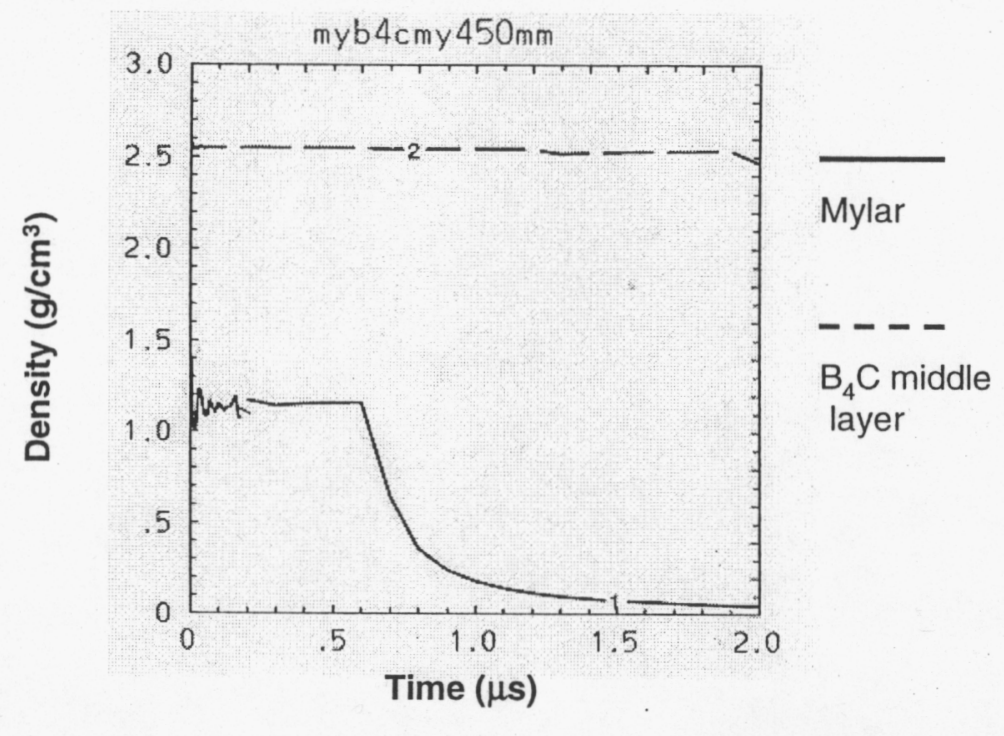

(b)

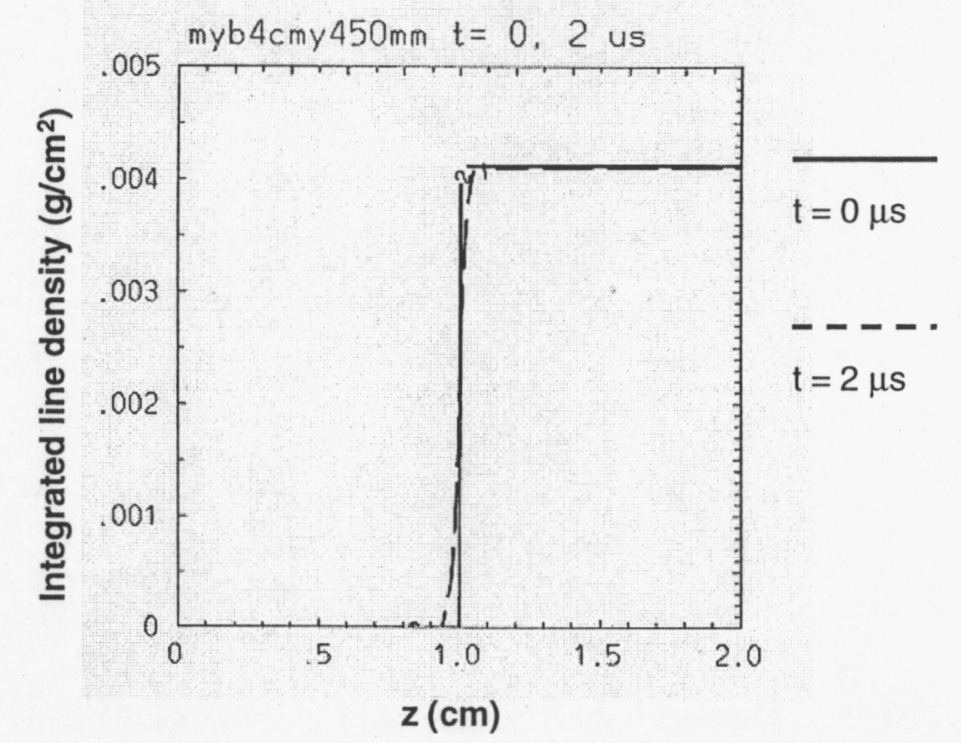

(c)

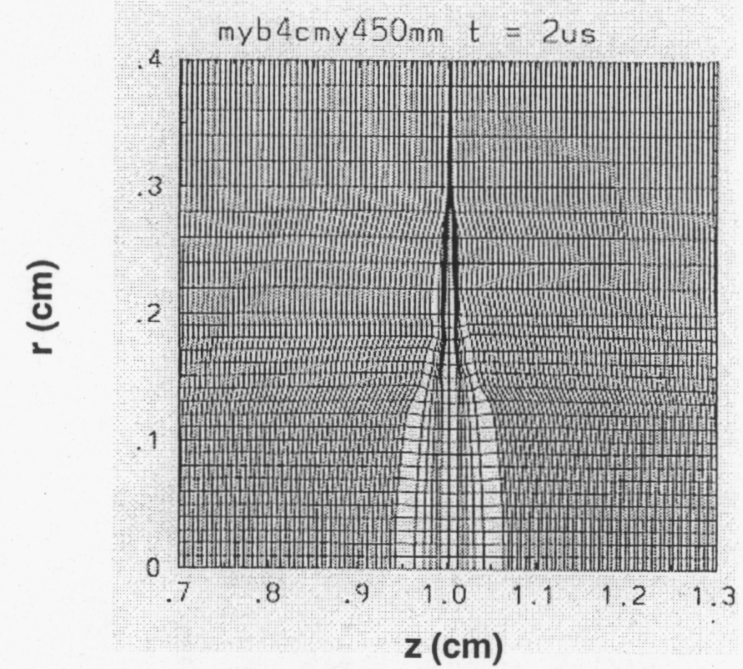

Fig. 5 Sandwich foil heated by DARHT-II beam with FWHM spot size of $4.5 \mathrm{~mm}$ 
(a)

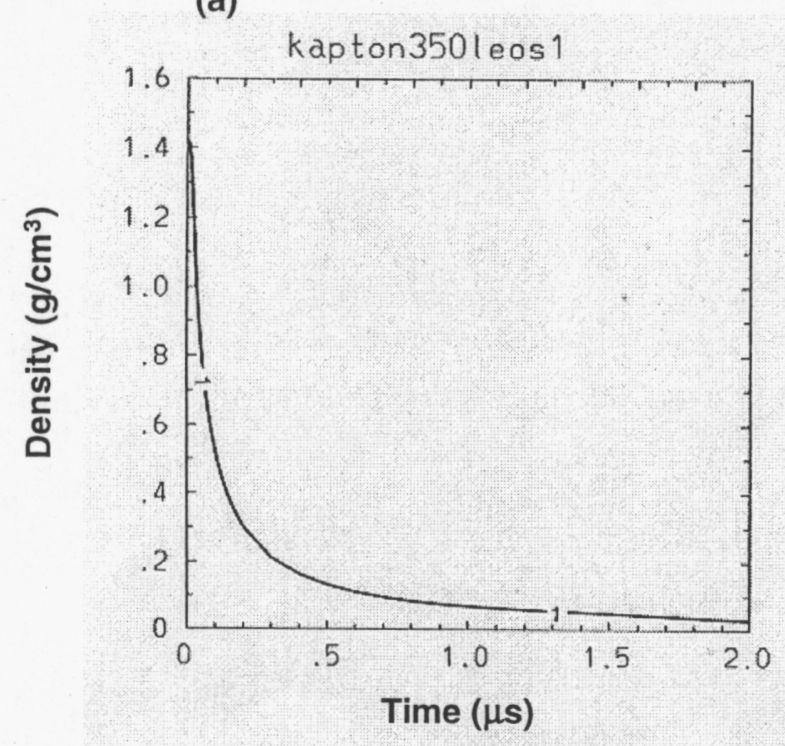

(c)

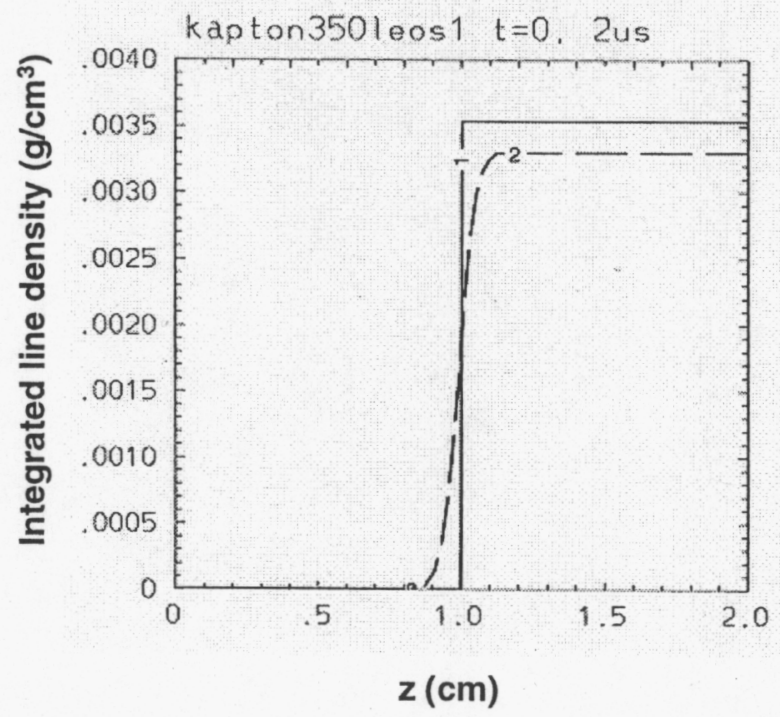

(b)

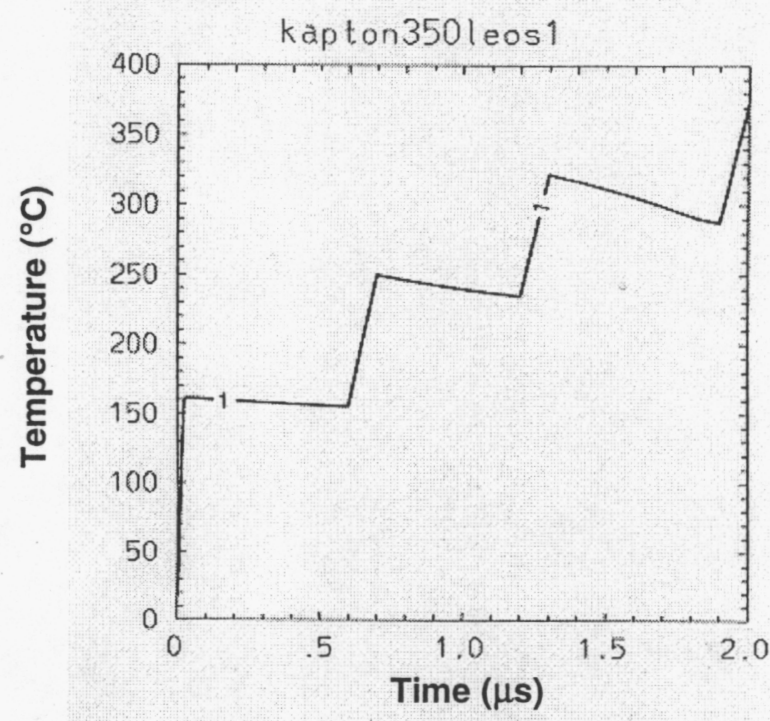

(d)

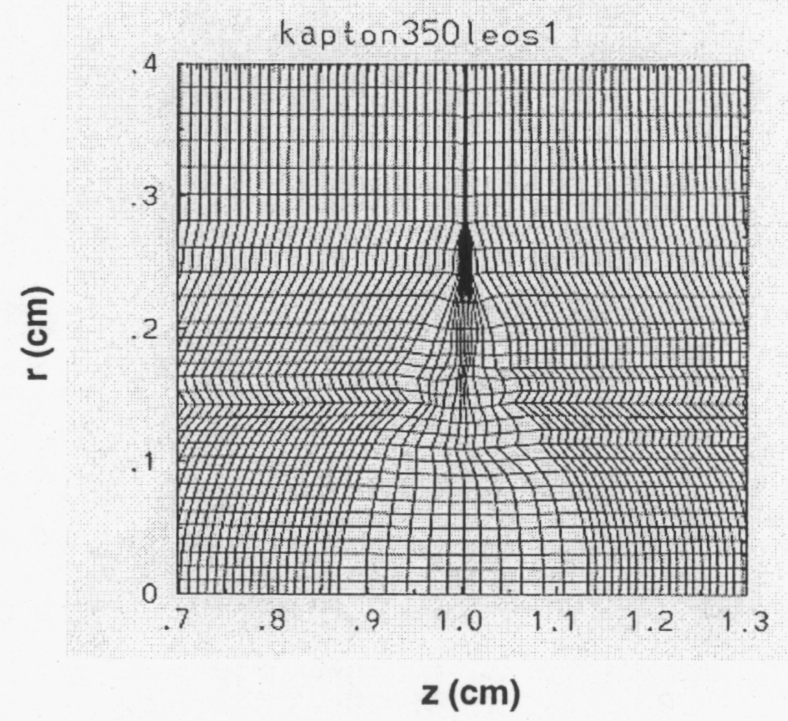

Fig 6. Kapton foil heated by DARHT-II beam with FWHM spot size of $3.5 \mathrm{~mm}$ 
(a)

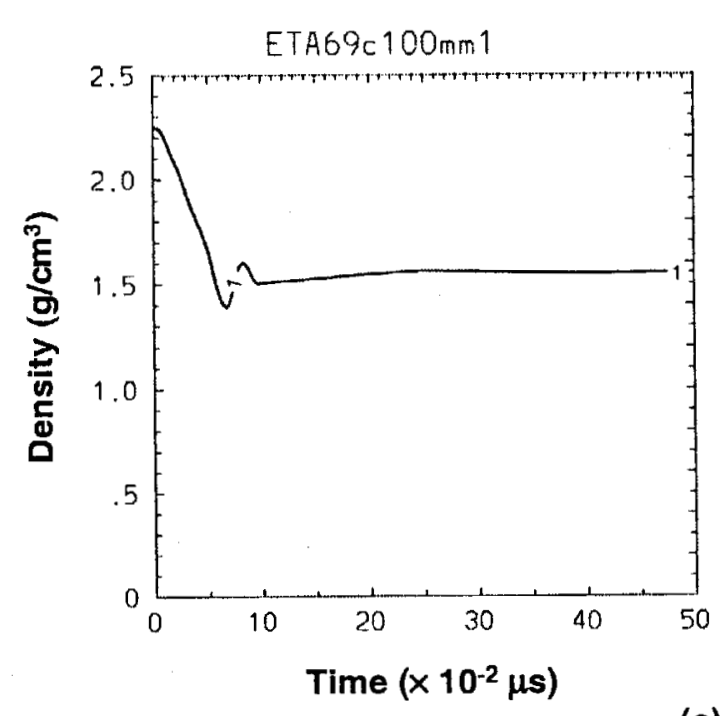

(b)

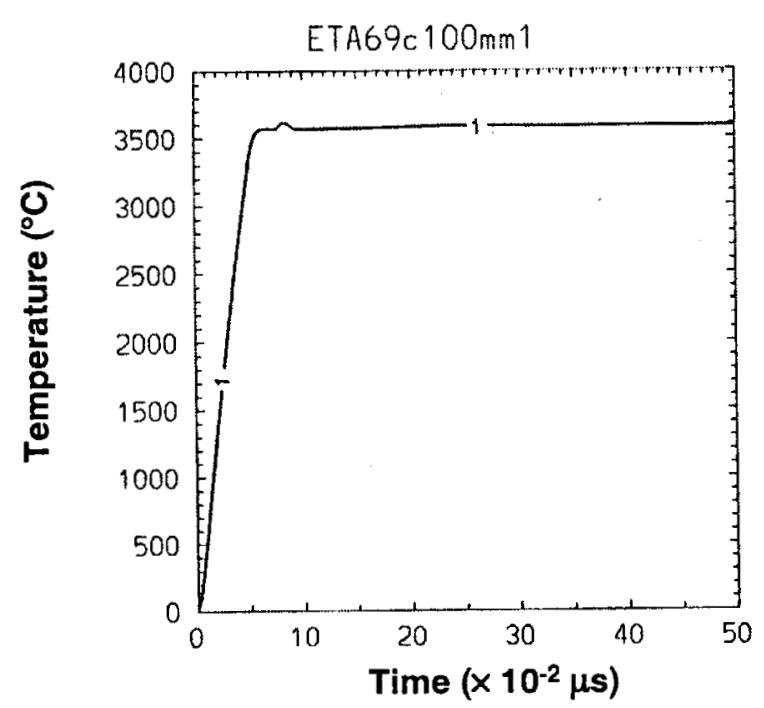

(c)

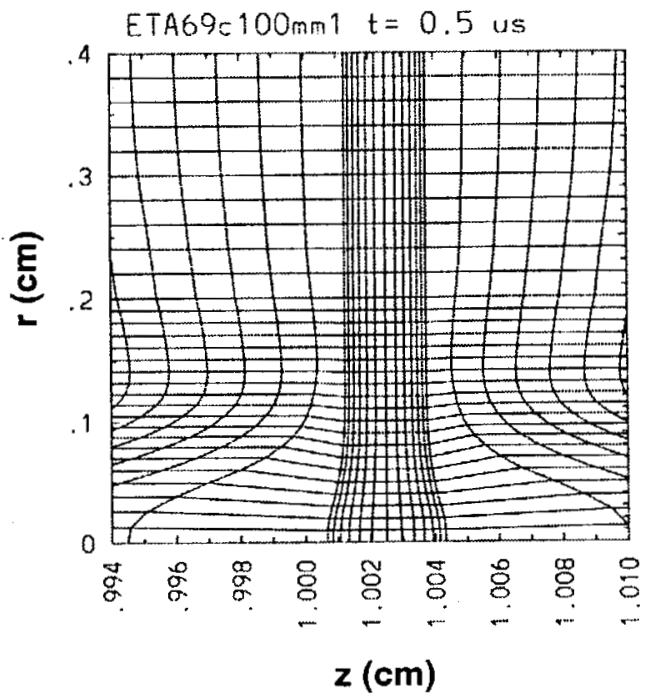

Fig. 7 Graphite foil heated by ETA-Il beam with FWHM spot size $=1 \mathrm{~mm}$ 